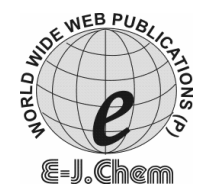

http://www.e-journals.net
ISSN: 0973-4945; CODEN ECJHAO

E-Journal of Chemistry

2009, 6(2), 377-384

\title{
Rapid Color Test Identification System for Screening of Counterfeit Fluoroquinolone
}

\author{
B K. SINGH* , D V. PARWATE ${ }^{\S}$ and S K. SHUKLA ${ }^{\#}$ \\ ${ }^{* \S}$ Department of Chemistry, \\ RTM Nagpur University, Nagpur-440033, India. \\ ${ }^{\#}$ Central Forensic Science Laboratory, \\ Ramanthapur, Hyderabad-500013, India. \\ singhbab2001@rediffmail.com
}

Received 9 August 2008; Accepted 10 September 2008

\begin{abstract}
The protocol of rapid identification system consists of three chemical color reactions; two group tests for fluoroquinolone class and a compound specific test each for norfloxacin, ciprofloxacin, gatifloxacin, ofloxacin, levofloxacin and sparfloxacin. The group color reactions are based on (a) Oxidizing behavior of quinolone and (b) Fluorine functional groups, both of which are characteristic of fluoroquinolone class. The compound specific color reactions are developed taking into consideration unique chemical behavior of each compound. The proposed chemical color tests have high selectivity/specificity, are ideal for screening purpose. The color of each test was defined by two standard color systems namely CIE lab and Munsell color. A suspected counterfeit tablet of any of the above mentioned drugs can be identified within 10-15 min using this rapid identification system.
\end{abstract}

Keywords: Counterfeit, Fluoroquinolones, Color test, CIE Lab, Munsell

\section{Introduction}

The problem of pharmaceutical counterfeiting has been increasing worldwide. The WHO is constantly monitoring incidence of counterfeiting around the world ${ }^{1}$. According to WHO database on counterfeit cases reported between 1982-1999 about 60\% counterfeit had no active ingredient and $45 \%$ of detected counterfeit products were antibiotics ${ }^{2}$.

While considering the first revelation of WHO report it becomes apparent that the first-line tests cannot be pharmacopoeial methods as they are expensive. This facilitates to bring in simple chemical color test (a) to increase the frequency of testing (b) to contain costs per analysis c) to enhance ease of operation ${ }^{3}$. The second revelation of the report bring into fore the need to develop methods for identification of counterfeit antibiotic preparations on priority basis ${ }^{4}$. 
In this study we have developed chemical color test for screening of some of the oral fluoroquinolones available in Indian market. The fluoroquinolones are widely prescribed broad-spectrum antibiotics. The compounds selected were norfloxacin, ciprofloxacin, gatifloxacin, ofloxacin, levofloxacin, and sparfloxacin (Figure 1).

\begin{tabular}{|c|c|c|c|c|}
\hline Compound & $\mathrm{R}_{1}$ & $\mathrm{R}_{2}$ & $\mathrm{R}_{3}$ & $\mathrm{R}_{4}$ \\
\hline Norfloxacin & $-\mathrm{C}_{2} \mathrm{H}_{5}$ & $-\mathrm{H}$ & & $-\mathrm{H}$ \\
\hline Ciprofloxacin & & $-\mathrm{H}$ & & $-\mathrm{H}$ \\
\hline Gatifloxacin & & $-\mathrm{OCH}_{3}$ & & $-H$ \\
\hline Sparfloxacin & & $-F$ & & $-\mathrm{NH}_{2}$ \\
\hline Levofloxacin & & & & -H \\
\hline Ofloxacin & & & & $-\mathrm{H}$ \\
\hline
\end{tabular}

Figure 1. Component structure of some members of fluorquinolone antibiotic class.

The proposed protocol has two group tests for fluoroquinolones class and a compound specific test. Thus a suspected formulation of any of the selected drugs can be screened with a set of three tests. The color tests were validated by determining sensitivity and specificity/selectivity ${ }^{5}$. Further, the color for each test was described by two internationally accepted standard color notations (a) Munsell notation, which is commonly used for describing color of presumptive tests ${ }^{6}$ (b) CIE Lab color scale, which is very sensitive and closer to human response.

\section{Experimental}

The working standards of norfloxacin, ofloxacin and levofloxacin drugs were provided by Ind-swift limited; gatifloxacin and ciprofloxacin by Lupin limited. 
The tablet samples for each drug were purchased form local drug stores and powdered with mortar-pestle. Similarly drug samples of other antibiotic classes for cross-reactivity study were procured and processed. The excipients used for testing interference were all of pharmaceutical grade.

\section{Reagents}

All chemicals used for reagent preparation were of analytical grade. For preparing solutions doubly-distilled water was used throughout.

\section{Color test}

The preparation of chemical color test reagents and procedure for performing each test is described below.

\section{Group test}

Oxidation of ferrous ammonium sulfate

Solution A: Ferrous ammonium sulfate solution $0.1 \%$ (w/v) in $1 \% \mathrm{H}_{2} \mathrm{SO}_{4}$.

Procedure: To the solid sample, $0.5 \mathrm{~mL}$ solution A was added followed by sodium bicabonate till effervescence ceased. Development of yellow-red color indicated presence of fluoroquinolones. The blank had no color.

Test for fluoride with Zr-EDTA-PV (Zirconium-Ethylene diamine tetracetic acidPyrocatechol violet) reagent

\section{Solution A}

The acetate buffer of $\mathrm{pH} 4.2$ was prepared by dissolving $3.7 \mathrm{~mL}$ glacial acetic acid and $2.177 \mathrm{~g}$ sodium acetate trihydrate in $50 \mathrm{~mL}$ water.

\section{Solution $B$}

$0.02 \mathrm{~g} \mathrm{ZrOCl}_{2}, 0.03 \mathrm{~g}$ EDTA and $0.001 \mathrm{~g}$ pyrocatechol violet were dissolved in water. To this $25 \mathrm{~mL}$ solution A was added and volume was made up to $100 \mathrm{~mL}$. This reagent is stable for nearly 2 weeks at room temperature $\left(\sim 30^{\circ} \mathrm{C}\right)$.

\section{Procedure}

The drug sample was fused with $50 \mathrm{mg}$ of $\mathrm{NaNO}_{3}$ in a wide mouth glass tube. After cooling, $25 \mathrm{mg} \mathrm{NH} \mathrm{N}_{4} \mathrm{Cl}$ was added and heating was resumed till effervescence ceased. After cooling, the solid mass was dissolved in $0.5 \mathrm{~mL}$ water and $0.5 \mathrm{~mL}$ solution $\mathrm{B}$ was added. The color change of solution B from blue to yellow indicated positive test for fluoroquinolones.

\section{Compound specific test}

Sparfloxacin: Oxidation with acidic dichromate

Solution A: $0.01 \mathrm{~N} \mathrm{~K}_{2} \mathrm{Cr}_{2} \mathrm{O}_{7}$ in $1 \mathrm{M}$ sulfuric acid

Procedure: The solid sample was treated with $0.5 \mathrm{~mL}$ of solution A in a spot plate and mixed by swirling. After a minute red-purple chromogen was formed. The control had yellow color.

\section{Ciprofloxacin and norfloxacin: Test with acid-base mixed indicator}

\section{Solution A}

(1:1), $0.1 \%$ Bromothymol blue (50\% alc.) and $0.1 \%$ methyl red (50\% alc.) 


\section{Procedure}

The solid sample was dissolved in $0.5 \mathrm{~mL} 0.1 \mathrm{~N} \mathrm{HCl}$ and allowed to stand for $2 \mathrm{~min}$. The supernatant was decanted and neutralized with $0.1 \mathrm{~N} \mathrm{NaOH}$ added in installments of $25 \mu \mathrm{L}$ till precipitation commenced. The precipitate obtained was either of ciprofloxacin or norfloxacin; it was washed 2-3 times with distilled water to remove any traces of excess acid or alkali. Finally, the precipitate was suspended in $0.5 \mathrm{~mL}$ water. 2-3 drops of solution A were added and after a few minutes color of supernatant liquid was observed. Norfloxacin and ciprofloxacin gave green and yellow color respectively, whereas the blank had faint red color.

Gatifloxacin, levofloxacin and ofloxacin: Test with cobalt thiocyanate

Solution A: 4N HCl

Solution B: $1.4 \mathrm{~g} \mathrm{CoCl}_{2} \cdot 6 \mathrm{H}_{2} \mathrm{O}$ and $0.9 \mathrm{~g} \mathrm{NH}_{4} \mathrm{SCN}$ in $100 \mathrm{~mL}$ distilled water.

Solution $C$ : Concentrated $\mathrm{HCl}$.

\section{Procedure}

To the solid sample $0.1 \mathrm{~mL}$ solution A was added and after mixing $0.2 \mathrm{~mL}$ solution $\mathrm{B}$ was added. When blue-green flaky precipitate was obtained, then immediately $0.2 \mathrm{~mL}$ solution $\mathrm{C}$ was added. After addition of solution $\mathrm{C}$ (a) for gatifloxacin the blue-green precipitate persisted (b) for ofloxacin the precipitate faded to white and disappeared after $5 \mathrm{~min}$ (c) in case of levofloxacin the precipitate disappeared immediately. The blank had pink color throughout.

\section{Validation of spot tests}

\section{Drug detection limit}

A serial dilution series of analyte was prepared and the test was performed. The limit of detection (LOD) for an analyte corresponds to the lowest concentration that gave all positives in five replicates ${ }^{6}$. This concentration multiplied by five was considered the operational detection limit (ODL). The tests were performed in triplicate on samples using quantity equivalent to ODL.

\section{Color}

The description of color was obtained using internationally accepted standard color scale. For determining color the visible transmittance or reflectance spectra were recorded and converted into device independent color parameters like CIE Lab and Munsell color.

\section{Visible spectra}

The transmittance spectra of solutions were recorded in the wavelength range 380-780 nm on Cintra 20e (GBC) spectrophotometer using water as reference. In case of test B.2 the precipitate was spread on a paper and its reflectance spectra was recorded on integrating sphere of Cintra 20e (GBC) spectrophotometer. For each sample three spectra were recorded and averaged data points were converted to spectrum and used for color analysis. The visible spectrum was used to compute CIE (Y, x, y) and CIE Lab values using Spectral 1.7 software.

\section{CIE Lab value}

The CIE Lab color scale is an approximately uniform color scale described by "Commission Internationale de l'Eclairage. The CIE Lab color space is organized in a cube form with three axes of cube representing $\mathrm{L}$, a and $\mathrm{b}$ value ${ }^{7}$. The CIE Lab color scale is extensively used to define true color in industries $e . g$. paint industry ${ }^{8}$ 


\section{Munsell color}

Conventionally, the Munsell notation for a chemical color test was obtained by visual comparison of test color with color chips in Munsell book. There is an alternative way of obtaining Munsell notations, through CIE (Y, x, y) to Munsell conversion tables produced by Newhall, Nickerson and Judd (1943). This conversion table has CIE (Y, x, y) equivalents of Munsell notation for 40 hues and 9 values at every second chroma step from zero to the loci of optimal colors ${ }^{7}$.

\section{Results and Discussion}

\section{Group test for fluoroquinolone class Group test (A.1)}

The quinolone moiety in fluoroquinolones was found to be capable of oxidizing ferrous to ferric. As reducing behavior is predominant among organic compounds and all other antibiotics act as reducing agents, thus the test becomes selective for fluoroquinolones. The oxidation of individual compound is $\mathrm{pH}$ dependent therefore by using acidic ferrous ammonium sulfate and subsequently adding sodium bicarbonate a very large range of $\mathrm{pH}$ from acidic to slightly alkaline can be traversed ${ }^{9}$.

\section{Group test (A.2)}

This test was based on conversion of organic fluorine to fluoride and then testing fluoride with Zr-EDTA-PV reagent. Conventionally, mineralization of organic fluorine compounds was carried out by sodium fusion method ${ }^{9}$ or incineration ${ }^{10}$ with $\mathrm{MgO}$, both of which are time consuming and color residues are often obtained. Thus we have devised the conversion through fusion with sodium nitrate, which is fast and does not leave any colored residue. The fluoride recovered was between 95 to $85 \%$. The fluoride formed was tested with $\mathrm{Zr}$ EDTA-PV reagent. In this test fluoride replaces pyrocatechol violet from $\mathrm{Zr-EDTA-PV}$ ternary complex by ligand-exchange mechanism and this was visually observable by discharging of blue color of the ternary complex to yellow, which was the color of uncomplexed pyrocatechol violet. The test was performed at $\mathrm{pH} \mathrm{4.2,} \mathrm{since} \mathrm{the} \mathrm{exchange}$ reaction ${ }^{11}$ was favored in $\mathrm{pH}$ range 3.5 to 5 . There are many other well studied methods for fluoride estimation like alizarin lake method and SPADNS ${ }^{12}$. The method described here has advantage of high stability of testing reagent and high tolerance for nitrate ions.

For determining selectivity of group tests for fluoroquinolones, the group tests were performed on other antibiotic classes and the results in Table 1 show that none of them interfered with either of the test. The sample tested positive for the above two tests were only subjected to testing for identification of individual members.

\section{Compound specific test sparfloxacin (B.1)}

On oxidation with mild acidic dichromate the sparfloxacin forms red-purple chromogen. This may be due to oxidation of aromatic amine group to quinone group. The resultant double ring quinoidal system offers a very sensitive and specific test for detection of sparfloxacin

\section{Ciprofloxacin and norfloxacin (B.2)}

Among fluoroquinolones ciprofloxacin and norfloxacin are unique because their isoelectric point is sufficiently separated from the two dissociation constant values as given in Table 2 . Thus when their solution in acid is slowly neutralized with alkali or vice versa, then in a $\mathrm{pH}$ range around isoelectric point there is sufficiently large population of zwitterions and solubility minima is reached. Whereas for other members of the group which are also 
ampholytes, the two pKa values are very close to isoelectric point, so that the zwitterions population in the dynamic system near isoelectric point is not sufficient enough to drive equilibrium towards solubility minima even at $0.1 \mathrm{M}$ concentration of drug. The differentiation test was performed with mixed indicator solution of bromothymol blue and methyl red. Norfloxacin and ciprofloxacin gave green (basic) and yellow (slight acidic) color respectively, whereas the blank had faint red color.

Table 1. Selectivity of A.1 and A.2 color reaction for fluoroquinolones.

\begin{tabular}{lcc}
\hline \multicolumn{1}{c}{ Compound } & A.1 & A.2 \\
\hline Norfloxacin & + & + \\
Gatifloxacin & + & + \\
Cefixime & - & - \\
Amoxicillin & - & - \\
Nalidixic acid & + & - \\
Erythromycin & - & - \\
Oxytetracycline & - & - \\
Lincomycim & - & - \\
Metronidazole & - & - \\
Nitrofurantoin & - & - \\
Ornidazole & - & - \\
Sulfamethoxazole & - & - \\
Chloramphenicol & - & - \\
Clavulanic acid & - & - \\
Piperazine & - & - \\
\hline
\end{tabular}

$(+)$ indicates that color reaction occur.

Table 2. Dissociation constant, isoelectric point and $\mathrm{pH}$ dependent distribution of zwitterions for some fluoroquinolones

\begin{tabular}{lcccc}
\hline \multicolumn{1}{c}{ Compound } & $\mathrm{pKa}_{1}$ & $\mathrm{pKa}_{2}$ & $\mathrm{pl}$ & $\begin{array}{c}\mathrm{pH} \text { range in which mole fraction of } \\
\text { Zwitterion } \geq 0.7\end{array}$ \\
\hline Ciprofloxacin & 4.34 & 10.03 & 7.19 & $4.7-9.6$ \\
Norfloxacin & 5.28 & 9.08 & 7.18 & $5.7-8.7$ \\
Pefloxacin & 5.84 & 7.22 & 6.53 & $6.4-6.6$ \\
Ofloxacin & 5.56 & 7.94 & 6.75 & $6.0-7.5$ \\
Gatifloxacin & 5.56 & 9.00 & 7.28 & $6.0-8.5$ \\
Levofloxacin & 5.59 & 7.94 & 6.77 & $6.0-7.5$ \\
Gemifloxacin & 5.76 & 8.40 & 7.08 & $6.2-8.0$ \\
\hline
\end{tabular}

$p K a=$ Dissociation constant $p l=$ Isoelectric point

Note: The values given in table were derived from $\mathrm{pH}$ titration curve. The dissociation constant value was average of values obtained from titration of deprotonated and protonated species against acid and alkali respectively.

\section{Gatifloxacin, levofloxacin and ofloxacin (B.3)}

The protonated secondary and tertiary bases were described to give bright blue-green flaky precipitate when treated with cobalt thiocyanate reagent also known as Scott test ${ }^{6}$. When fluoroquinolones were treated with cobalt thiocyanate reagent in presence of $4 \mathrm{~N} \mathrm{HCl}$ then gatifloxacin, levofloxacin and ofloxacin gave neutral blue-green ion-pair complex. When concentrated $\mathrm{HCl}$ was added in the second step, the blue-green precipitate was converted to green for gatifloxacin, white for ofloxacin and disappeared completely in case of levofloxacin. 
The other fluoroquinolones did not give this test under neutral or acidic conditions. It is note worthy that the test can be used to differentiate between ofloxacin and levofloxacin which are enantiomers.

The specificity of test for individual compounds was verified by studying intra-group cross reactivity against oxolinic acid, enoxacin, pefloxacin, gemifloxacin and lomefloxacin in addition to the studied compounds. The above mentioned drugs did not interfere with the test.

\section{Detection limit and color}

The value of LOD (limit of detection) for tests described is shown in Table 3. In case of group test a single value of LOD is given since all the compounds studied have nearly equal LOD for test A.1, only in case of A.2 sparfloxacin has lower LOD equal to $1 \mathrm{mg}$. The color values are given for both LOD and ODL (operational detection limit) in order to define lower and upper limits of color range for a test.

Table 3. Drug detection limit and colors produced in test A. 1 to B.3 for compounds of fluoroquinolone antibiotic class.

\begin{tabular}{llcccc}
\hline Test & \multicolumn{1}{c}{ Analyte } & $\begin{array}{c}\text { ODL } \\
\text { LOD, mg }\end{array}$ & $\begin{array}{c}\text { Observed } \\
\text { color }\end{array}$ & $\begin{array}{c}\text { CIE, } \\
\text { L, a, b }\end{array}$ & $\begin{array}{c}\text { Munsell } \\
\text { color }\end{array}$ \\
\hline A.1 & Fluoroquinolones & 0.3 & Yellow & $88,-2,22$ & 5 Y 9/8 \\
& & 1.5 & Yellow red & $72,30,111$ & 7.5 YR 7/18 \\
A.2 & Fluoroquinolones & 2 & Dull yellow & $83,-1,18$ & $2.5 \mathrm{Y} 8 / 2$ \\
& & 10 & Bright yellow & $87,-4,36$ & $5 \mathrm{Y} 9 / 6$ \\
B.1 & Sparfloxacin & 0.1 & Pink & $83,15,3$ & $10 \mathrm{RP} 8 / 4$ \\
& & 0.5 & Red-purple & $50,40,2$ & $7.5 \mathrm{RP} 5 / 10$ \\
B.2 & Ciprofloxacin & 5 & Yellow & $88,-11,59$ & $7.5 \mathrm{Y} 9 / 8$ \\
& & 25 & Dark yellow & $83,-10,74$ & $7.5 \mathrm{Y} 8 / 10$ \\
B.2 & Norfloxacin & 5 & Green & $76,-24,58$ & $5 \mathrm{GY} 7 / 8$ \\
& & 25 & Deep green & $70,-26,42$ & $7.5 \mathrm{GY} 7 / 10$ \\
B.3 & Gatifloxacin, Levo & 2 & Blue green & $76,-53,-20$ & $10 \mathrm{BG} 7 / 12$ \\
& -floxacin, Ofloxacin, & 10 & Blue green & $83,-39,-10$ & $7.5 \mathrm{BG} 8 / 8$ \\
\hline
\end{tabular}

All the tests when performed on tablet samples from different manufacturers gave similar results as standards. To reaffirm this observation interference from excipients, diluents and additives commonly used in solid drug formulations was studied. It was found that dextrose, sodium chloride, titanium dioxide, galactose, lactose, mannitol, sucrose, starch, cellulose, gelatin, magnesium stearate and polyethyleneglycol did not interfere with these tests.

\section{Conclusion}

The rapid identification system based on a set of three chemical color reactions can be used for screening of counterfeit solid formulation of studied fluoroquinolones containing no active ingredient. The sensitivity of described tests was low but due to high selectivity/ specificity they are ideal for screening purpose. The system has virtues of simplicity, fastness, low cost and ease of operation.

\section{Acknowledgements}

1 The authors thank Head, Department of Chemistry, Rashtrasant Tukadoji Maharaj Nagpur University for providing laboratory facilities. 
2 One of the authors Ms. Babita Singh would like to thank Central Forensic Science Laboratory, Directorate of Forensic Science, Ministry of Home Affairs, Hyderabad for providing her fellowship.

\section{References}

1. World Health Organization. Department of Essential Drugs and Other Medicines, Guidelines for the development of measures to combat counterfeit drugs. 1999, WHO/EDM/ QSM/99.1, Geneva

2. Wondemagegnehu E, Counterfeit and substandard drugs in Myanmar and Vietnam, EDM Research Series, No. 29, 1999, WHO/EDM/QSM/99.3, Geneva.

3. Jähnke R W O, Pharm India, 2004, 66 (10), 1187.

4. Hu C Q, Zou W B, Hu W S, Ma X K, Yang M Z, Zhou S L, Sheng J F, Li Y, Cheng S $\mathrm{H}$ and Xue J, J Pharm Biomed Anal., 2006, 40, 68.

5. EMEA, European Medicines Agency. Validation of Analytical Procedures: Text and Methodology, 1995, CPMP/ICH/381/95.

6. O' Neal C L, Crouch D J and Fatah A A, Forensic Sci Int., 2000, 109, 189.

7. Wyszecki G and Stiles W S, Color science, Concepts and Methods: Quantitative Data and Formulas, John Wiley \& sons, Inc, New York, 1967.

8. Tücks A and Beck H P, J Solid State Chem., 2005, 178, 1145.

9. Feigl F, Spot tests Vol II, Organic applications, $4^{\text {th }}$ ed., Elsevier, Amsterdam, 1954.

10. Jungreis E and Ben-Dor L, Organic spot test analysis, Svehla G, Ed. Quantitative analytical Chemistry, Elsevier, Amsterdam, 1980, 10.

11. Balaji T and Matsunaga H, Anal Sci., 2005, 23, 973.

12. Campbell AD, Pure Appl Chem., (IUPAC) 1980, 59(5), 695. 


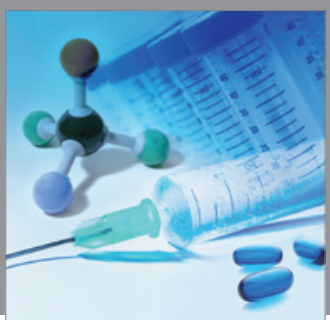

International Journal of

Medicinal Chemistry

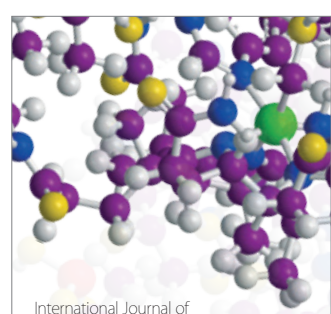

Carbohydrate Chemistry

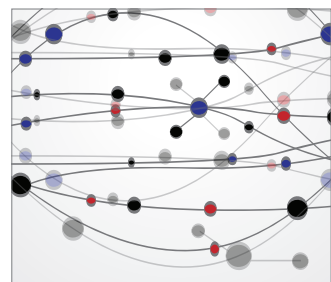

The Scientific World Journal
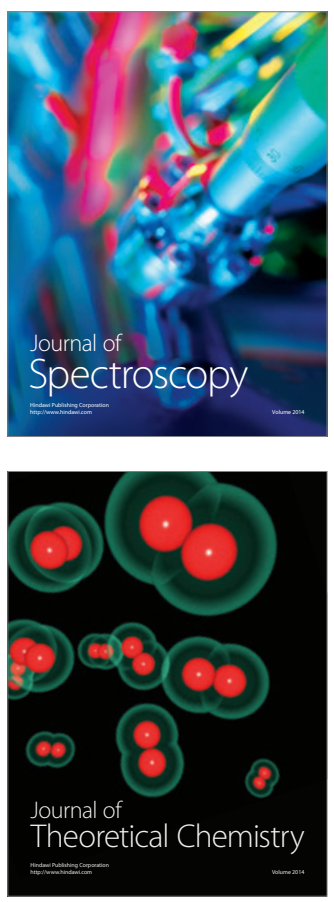
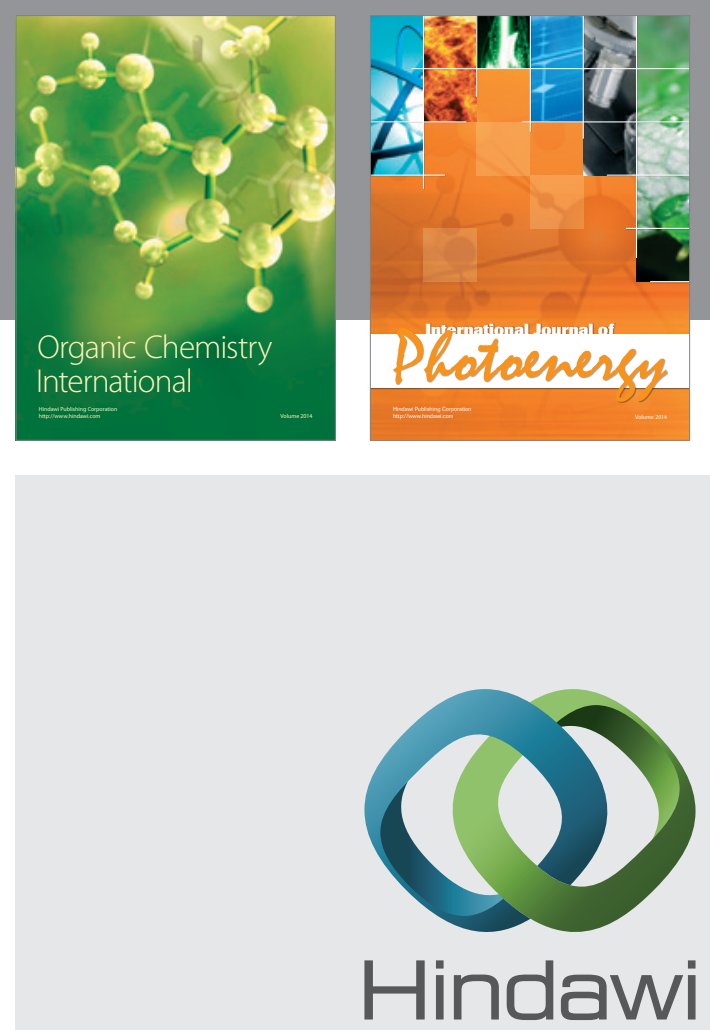

Submit your manuscripts at

http://www.hindawi.com
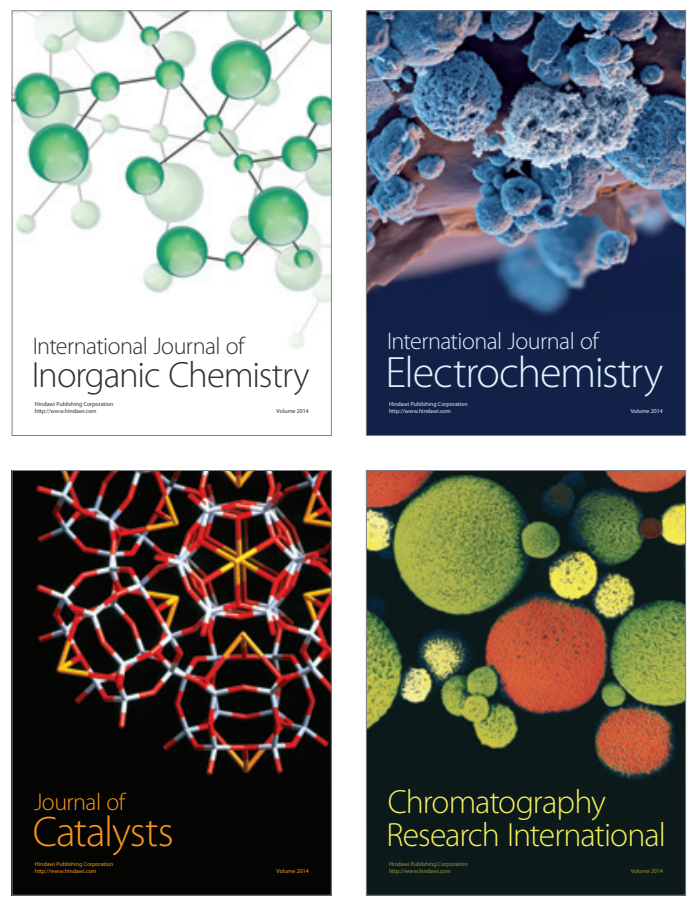
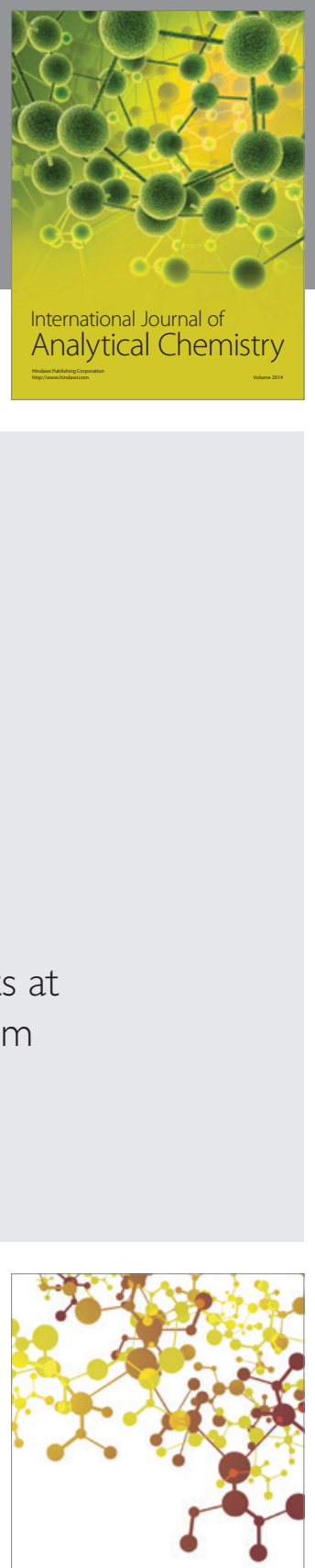

Journal of

Applied Chemistry
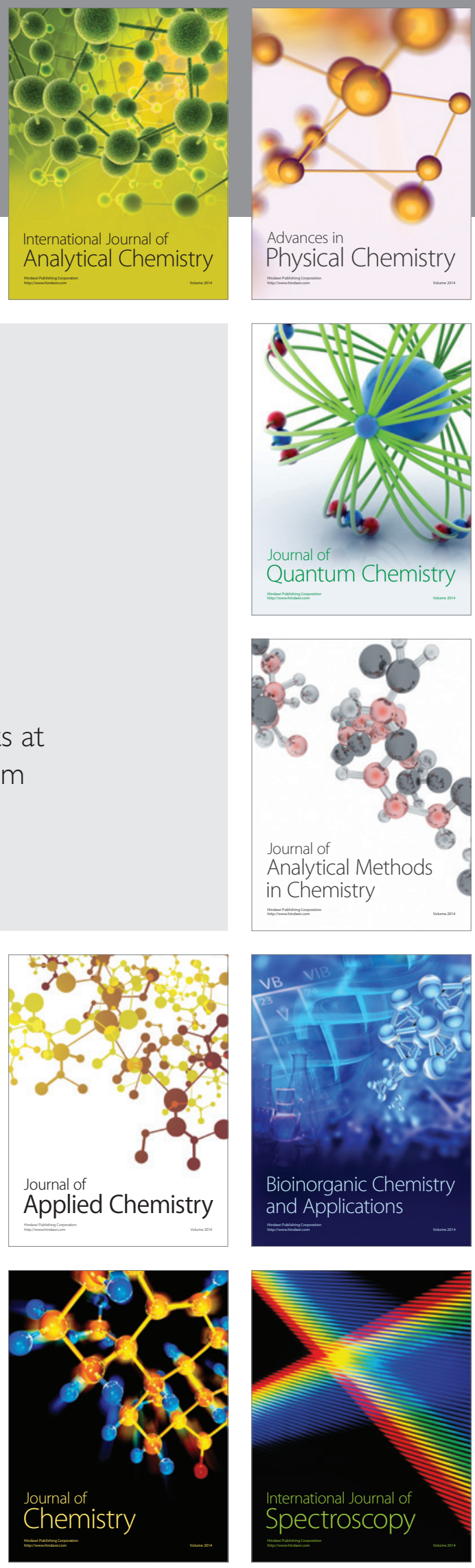